\title{
O PROCESSO DE AVALIAÇÃO DO ESTÁGIO PROBATÓRIO NOS CINCO MAIORES HOSPITAIS ESTADUAIS DE PERNAMBUCO: UM RELATO DE EXPERIÊNCIA.
}

\section{$\underline{\text { T. L. de ALMEIDA }}{ }^{1}$}

${ }^{1}$ Escola de Governo de Saúde Publica de Pernambuco, Residência em Saúde Coletiva

E-mail para contato: tatiana_lial@hotmail.com

\begin{abstract}
RESUMO - O trabalho tem a intenção de discutir o processo de avaliação de estágio probatório no âmbito da gestão da saúde estadual nos cinco maiores hospitais. É realizado a analise através da experiência em reuniões da gestão da SES-PE com os Rhs dos hospitais. Apesar de serem hospitais com semelhanças entre si, existem inúmeras particularidades que podem ser observadas através do relato nas reuniões. Então é possível verificar que esse processo ainda está em construção, onde os Rhs tem déficit de pessoal, e as chefias precisam compreender melhor a avaliação.
\end{abstract}

Palavras Chaves: processo avaliativo; processo pedagógico; saúde; gestão hospitalar.

\begin{abstract}
The paper intends to discuss the process of evaluation of probationary stage in the scope of state health management in the five largest hospitals. The analysis is carried out through the experience in meetings of the management of the SES-PE with the Rhs of the hospitals. Although they are hospitals with similarities to each other, there are numerous particularities that can be observed through reporting at meetings. So it is possible to verify that this process is still under construction, where the Rhs have a staff shortage, and the managers need to understand the evaluation
\end{abstract}

Keywords: Evaluation process; pedagogical process; Cheers; hospital management.

\section{INTRODUÇÃO}

O Estágio Probatório é o período que o servidor, aprovado em concurso público, passa nos primeiros três anos de atividade no serviço público, além de obter estabilidade, durante esse período o servido é avaliado pela sua chefia imediata nos critérios de idoneidade moral, assiduidade, disciplina e eficiência, onde é garantido aptidão para o cargo. (LEI 6.123/1968 PE) 
No estado de Pernambuco atualmente existem as legislações especificas que normatizam o estagio probatório, entre elas o Estatuto do Servidor Estadual (Lei 6123/1968) que no art. 43 traz o estágio probatório, o decreto $n^{\circ} 44.226$, de 15 de março de 2017, que define os critérios e procedimentos para a avaliação especial do estágio probatório, e a portaria $\mathrm{n}^{\mathrm{o}}$ 889, de 21 de março de 2017 que lança o novo modelo do formulário de avaliação e o Decreto $n^{\circ} 44.949$, de 4 de setembro de 2017 que faz alterações ao Decreto nº 44.226 .

Na Secretaria estadual de saúde, o acompanhamento do estágio probatório é realizado pela Gerência de Políticas e Regulação do Trabalho (GPRT), que faz parte da Diretoria de Geral de Gestão do Trabalho (DGGT), por sua vez é parte da Secretaria Executiva Gestão do Trabalho e Educação em Saúde (SEGTES).

São acompanhados todos os serviços de saúde estadual, entre eles, hospitais, laboratórios, farmácia, serviço de verificação de óbito. Nesse trabalho especificamente será tratado considerações apenas sobre os cinco maiores hospitais estaduais localizados na capital, Recife. O decreto 44.226 coloca que são envolvidos no processo de avaliação do estágio probatório: a Secretaria de Administração; a Comissão de Avaliação Especial de Desempenho em Estágio Probatório; a chefia mediata e/ou imediata do servidor avaliado; IV - a Unidade de Recursos Humanos de cada órgão ou entidade; e o servidor avaliado.

Na unidade de saúde o processo avaliativo do estágio probatório é mediado pelos Recursos humanos (Rh) da instituição. Onde o mesmo faz o monitoramento do período em que cada servidor precisará ser avaliado e repassa as fichas avaliativas e informações para a sua chefia imediata. Cada unidade de saúde estudada possui uma comissão de avaliação especial de desempenho em estágio probatório, essa comissão é responsável pelos julgamentos de recursos contra as avaliações realizadas, e por emitir o parecer conclusivo ao final das três avaliações, cada comissão é formada por cinco membros.

O servidor precisa ser avaliado três vezes nos três primeiros anos depois de nomeado servidor público. A primeira etapa da avaliação ocorre depois de dez meses de serviço, a segunda etapa depois de vinte meses de serviço e a terceira etapa depois de trinta meses de serviço. O processo considera as avaliações por etapa e a média das avaliações ao termino das três etapas, sendo o servidor avaliado por critério e por media final.

\section{MATERIAIS E MÉTODOS}

Durante o estágio da residência em saúde coletiva, realizado na Gerência de Políticas e Gestão do Trabalho da Secretaria Estadual de Saúde de Pernambuco nos meses de outubro e novembro de 2017, foi possível acompanhar reuniões entre o setor de estagio probatório e os recursos humanos dos cinco maiores hospitais de Pernambuco, localizados na capital, Recife.

Será descrito e analisado esse processo formador da avaliação do estágio probatório nessas unidades, a partir da vivência nessas reuniões. Foi realizada uma reunião em cada hospital, para ajustar informações sobre o novo decreto que trouxe mudanças recentes na avaliação. Para não identificar os referidos hospitais, chamarei aleatoriamente de H1, H2, H3, H4 e H5.

As reuniões foram realizadas nos hospitais, com o responsável e/ou representação dos recursos humanos (Rh) com participação ou não comissão de avaliação especial de 
desempenho em estágio probatório da instituição.

\section{RESULTADOS E DISCUSSÃO}

Em todos os hospitais foi levado um roteiro de apresentação das normas da avaliação do estagio probatório, ficha impressas (avaliação, parecer conclusivo, situações adversas, e recurso), e um ckeck list para confirmar algumas informações, como por exemplo, se estava recebendo e-mails, se está com algum problema nas avaliações, se tem algum servidor com avaliação de servidor tido como inapto, dentre outras.

No H1 a reunião foi realizada com dois responsáveis pelos Rh, que também fazem parte da comissão e mais duas pessoas membros da comissão. Foi explicado inicialmente o processo de avaliação do estágio probatório. E o novo papel da comissão. O decorrer da reunião foi tranquilo, surgiram algumas duvidas do novo processo, alguns anseios do $\mathrm{Rh}$ enquanto ao numero de avaliação, já que recebeu um grande número de servidores novos, e surgiram novas ideias de instrumentos para melhorar o processo.

No $\mathrm{H} 2$ a reunião foi realizada apenas com a responsável do $\mathrm{Rh}$. A conversa foi tranquila, onde a pessoa do $\mathrm{Rh}$ já estava esclarecida sobre as novas normas de avaliação, foram apenas relatados por elas alguns casos de servidores específicos que pode ocasionar em algum problema no processo avaliativo.

No H3 a reunião foi realizada com duas pessoas do Rh, uma delas sendo a responsável pelos encaminhamentos da avaliação. Foi explicado o novo processo de avaliação, e a responsável do $\mathrm{Rh}$ expressou preocupação em relação ao processo avaliativo de algumas chefias, e solicitou até que possa ser marcada uma nova reunião com a presença dessas pessoas.

No H4 a reunião aconteceu com a responsável do Rh e três membros da comissão. A servidora do Rh já é experiente, e a maioria da comissão são membros novos. Foi explicado o processo de avaliação e o papel da comissão. Nesse momento foi falado por algumas das pessoas presentes situações difícil com servidores novos, como por exemplo, dificuldade em preencher formulários, e administrar medicamentos em pacientes. Foi reforçado o papel pedagógico do processo do estagio probatório, e reforçado algumas recomendações como ensinar no serviço, ministrar capacitações.

H5 a reunião aconteceu com um representante do Rh, e três membros da comissão. Foi explicado inicialmente o processo de avaliação do estágio probatório. Os membros da comissão são todos novos no processo, e o representante do Rh não interagiu muito, a responsável do $\mathrm{Rh}$ pelas avaliações do estágio probatório estava em férias. A reunião foi bem acalorada, onde os membros da comissão estavam com muitas duvidas e receosos em relação ao processo avaliativo, pois no hospital tem um caso de judicialização de um servidor que foi avaliado como inapto. As duvidas foram esclarecidas, e deixo clara a disponibilidade do contato e de novas reuniões caso seja necessário.

\section{CONCLUSÃO}

Após a vivência nesses momentos de reunião, foi possível conhecer um pouco de como se dá as relações nos hospitais, e que apesar de similaridades, como ser estadual, 
está localizado na capital do estado e ser de alta complexidade, cada um tem diversas particularidades. Os Rh tem déficit de pessoal, os servidores trabalham sobrecarregados, as unidades que receberam um grande quantitativo de novos servidores sentem ainda mais a sobrecarga quando está no período de avaliação.

Esse processo é de certa forma novo nos serviços de saúde, para os cargos de analistas e assistentes, visto que esse é o primeiro concurso que convocaram esses cargos. Então é considerado normal algumas dificuldades e dúvidas. Ainda precisa ser reforçado com todos os envolvidos no processo na instituição (chefia, servidor, Rh), da importância desse período para explorar a sua potencialidade, onde o servidor está conhecendo a instituição e se adequando ao serviço.

Foi também constante as queixas em relação a novos servidores, do tipo que não estão preparados técnicamente, que não se adaptam a rotina do serviço, que não tem um bom relacionamento interpessoal. Portanto esse processo da avaliação em estágio probatório está em construção tanto no serviço, como com as relações de trabalho.

\section{REFERÊNCIAS}

PERNAMBUCO. Lei Complementar no 194, de 09 de dezembro de 2011. Disponível em: $<$ http://legis.alepe.pe.gov.br/arquivoTexto.aspx?tiponorma $=2 \&$ numero=194\&complemento $=0 \&$ ano $=2011 \&$ tipo $=\& u r l=>$. Acesso em: 14 de novembro de 2017.

PERNAMBUCO. Lei Complementar $\mathbf{n}^{0}$ 332, de 22 de junho de 2016. Disponível em: < http://legis.alepe.pe.gov.br/arquivoTexto.aspx?tiponorma $=2 \&$ numero $=332 \&$ complemento $=0$ $\&$ ano=2016\&tipo=\&url=>. Acesso em: 14 de novembro de 2017.

PERNAMBUCO. Decreto $n^{\circ}$ 44.949, de 4 de setembro de 2017. Disponível em: < http://legis.alepe.pe.gov.br/arquivoTexto.aspx?tiponorma $=6 \&$ numero $=44949 \&$ complemento $=0 \&$ ano $=2017 \&$ tipo $=\& u r l=>$. Acesso em: 14 de novembro de 2017. 